Article

\title{
Following Enzyme Activity with Infrared Spectroscopy
}

\section{Saroj Kumar and Andreas Barth *}

Department of Biochemistry and Biophysics, Stockholm University, Stockholm, Sweden;

E-Mail:saroj@dbb.su.se

* Author to whom correspondence should be addressed; E-Mail: Andreas.Barth@dbb.su.se; Tel.: +46-8-162452; Fax: +46-8-155597.

Received: 24 January 2010; in revised form: 20 February 2010 / Accepted: 6 March 2010 / Published: 25 March 2010

\begin{abstract}
Fourier transform infrared (FTIR) spectroscopy provides a direct, "on-line" monitor of enzymatic reactions. Measurement of enzymatic activity is based on the fact that the infrared spectra of reactants and products of an enzymatic reaction are usually different. Several examples are given using the enzymes pyruvate kinase, fumarase and alcohol dehydrogenase. The main advantage of the infrared method is that it observes the reaction of interest directly, i.e., no activity assay is required to convert the progress of the reaction into an observable quantity.
\end{abstract}

Keywords: vibrational spectroscopy; infrared spectroscopy; ATR; FTIR; enzyme activity

\section{Abbreviations}

ATR attenuated total reflection

FTIR Fourier transformed infrared

IR infrared

PEP phosphoenolpyruvate

PK pyruvate kinase

ADH alcohol dehydrogenase 


\section{Introduction}

Enzymes are fundamental to life and are used in many biotechnological processes. Therefore, enzymatic activity is an important parameter in many contexts. In favourable cases an enzymatic reaction can be directly followed with spectroscopy in the UV or visible spectral range. In these cases the substrate or product of an enzymatic reaction is coloured, like for the $\mathrm{NAD}^{+} / \mathrm{NADH}$ system, or light is emitted in the course of the reaction, like in the reaction of luciferase with ATP and luciferin.

In most cases, however, substrate and product cannot be distinguished in the UV or visible range of the spectrum and enzyme activity has to be determined indirectly. For this, coloured or fluorescent substrate analogues have been developed or the enzymatic reaction of interest has to be coupled to auxiliary enzymatic reactions that can be followed in the UV or visible spectral range. An example is the coupled enzyme assay for the measurement of ATPase activity. The assay couples ATP hydrolysis catalysed by the enzyme of interest to the oxidation of NADH via the auxiliary enzymes pyruvate kinase and lactate dehydrogenase.

This "state of the art" of activity measurements implies that for a "new" enzymatic reaction an activity assay or a suitable substrate analogue has to be developed. This is often time-consuming, the modification of the substrate may affect the activity and applying the activity assay can be cumbersome, slow and may be limited to specific experimental conditions required by the assay. Therefore, in order to speed up the development of biotechnological processes and to save costs, techniques that monitor enzymatic reactions directly are highly desirable.

Infrared spectroscopy can provide such a direct, "on-line" monitor of enzymatic reactions, because the spectrum depends on the structure and environment of a molecule. When a molecular structure is modified in an enzymatic reaction, the infrared spectrum is altered and changes in infrared absorption can be followed to monitor the progress of the reaction. Measurements of enzyme activity with infrared spectroscopy are relatively straightforward and several studies have been published comprising urea hydrolysis by urease [1,2], cefoxitin hydrolysis by $\beta$-lactamase [3], deacylation of cinnamoyl-chymotrypsin [4], ATP hydrolysis by the $\mathrm{Ca}^{2+}$-ATPase [5-7], dephosphorylation of fructose 1,6-bisphosphate by fructose-1,6 bisphosphatase [8] and of 4-nitrophenylphosphate by alkaline phosphatase [9], oxidation of D-glucose by glucose oxidase [10], hydrolysis of sucrose by $\beta$-fructofuranosidase [11-13], of maltose by amyloglucosidase [13] and of starch by amylogucosidase $[14,15]$ and $\alpha$-amylase $[15,16]$, hydrolysis of amides $[17,18]$ and synthesis of hydroxamic acid derivatives [18] by amidase, hydrolysis of several organophosphorus compounds by diisopropyl fluorophosphatase [19], the reaction of $\alpha$-ketoglutarate and Ala to Glu and pyruvate by glutamicpyruvic transaminase [20], consumption of oxalate and production of formate and $\mathrm{CO}_{2}$ by oxalate decarboxylase [21], and acetone-butanol fermentation [22].

We have previously followed ATP hydrolysis by the $\mathrm{Ca}^{2+}$-ATPase with infrared spectroscopy [5-7]. Enzyme activity could be measured with only $7.5 \mu \mathrm{g}$ enzyme being needed and the infrared activity values compared well to those of the traditional coupled enzyme assay. In these measurements, the enzymatic reaction was started by the photolytic release of ATP from a biologically inactive photosensitive precursor molecule-caged ATP $[5,6]$. Because this method is not generally applicable with commercial equipment, we explore here a simpler approach to follow enzymatic activity. Using a 
commercial attenuated total reflection (ATR) setup, we monitored the enzymatic reactions of pyruvate kinase, alcohol dehydrogenase and fumarase.

Pyruvate kinase (PK) (EC 2.7.1.40) is a key enzyme of the glycolytic pathway that catalyses the transfer of phosphate from phosphoenolpyruvate (PEP) to adenosine diphosphate (ADP). The physiological reaction of PK proceeds in two chemical steps. The first step is phosphoryl transfer from PEP to ADP which produces ATP and the enolate of pyruvate [23]. The second step is the addition of a proton to the enolate of pyruvate to produce pyruvate [24] (Scheme I).

Scheme I. Conversion of PEP to pyruvate by PK.<smiles>C=C(OP(=O)([O-])[O-])C(=O)[O-]</smiles>
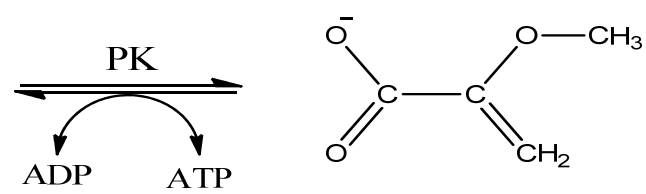

Fumarase (EC 4.2.1.2) is an enzyme of the tricarboxylic acid (Krebs) cycle which reversibly catalyses the conversion from malate to fumarate [25] (Scheme II).

Scheme II. Conversion of malic acid to fumaric acid by fumarase.<smiles>O=C(O)CC(O)C(=O)O</smiles><smiles>O=C(O)/C=C/C(=O)O</smiles>

Alcohol dehydrogenase (ADH) (EC 1.1.1.1) is a member of a general class of enzymes called oxidoreductases that facilitate the interconversion of alcohols to aldehydes. The reactions need the coenzyme nicotinamide adenine dinucleotide $\left(\mathrm{NAD}^{+}\right)$(Scheme III).

Scheme III. Conversion of ethanol to acetaldehyde by alcohol dehydrogenase.

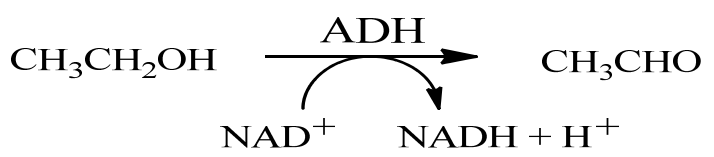

\section{Results and Discussion}

\subsection{Experimental Approach}

Enzyme activity was monitored in the following way: enzyme and substrate were manually mixed and placed on an ATR crystal. Then a background spectrum and a series of sample spectra were recorded. Each of the difference spectra shown in the following reflects the difference in absorbance 
between a particular sample spectrum and the background spectrum, i.e., the absorbance change that occurred in the time between recording background and sample spectrum. In this way the much stronger absorptions of water, buffer and protein do not contribute to the difference spectra shown, as long as they remain constant. Buffer signals in the difference spectra are expected, if the catalytic reaction involves proton uptake or release. Small protein signals were observed, because protein settled on the surface of the ATR crystal. This was however outside the spectral ranges evaluated for monitoring the enzymes.

\subsection{Infrared Difference Spectra of the Catalytic Reaction of PK}

The absorbance changes due to the catalytic reaction of PK are shown in Figure 1. They represent the difference in absorbance between the background spectrum recorded within $50 \mathrm{~s}$ after mixing and spectra recorded at later times. Negative bands are due to substrate consumption and positive bands due to product formation. The series of solid line spectra in Figure 1A represent the catalytic reaction during 30 minutes and the dotted line is the last spectrum of the control experiments. The positive band at $1174 \mathrm{~cm}^{-1}$ is due to the formation of pyruvate [26], and the negative bands at $974 \mathrm{~cm}^{-1}$ and $1103 \mathrm{~cm}^{-1}$ are caused by PEP consumption [27]. Similarly, absorption at 1240 , and $918 \mathrm{~cm}^{-1}$ is assigned to ATP production while the negative band at $941 \mathrm{~cm}^{-1}$ is due to ADP consumption [28,29]. These bands are assigned as follows: the band at $1174 \mathrm{~cm}^{-1}$ is due to the $\mathrm{C}-\mathrm{CH}_{3}$ stretching vibration of pyruvate [30], and the bands at 1103 and $974 \mathrm{~cm}^{-1}$ are due to $-\mathrm{PO}_{3}{ }^{2-}$ stretching vibrations of PEP [27]. The bands arising at $1240 \mathrm{~cm}^{-1}$ and $918 \mathrm{~cm}^{-1}$ are from the $\beta-\mathrm{PO}_{2}^{-}$and the P-O-P groups of ATP, respectively, while the $\beta-\mathrm{PO}_{3}{ }^{2-}$ and P-O-P groups of ADP are observed at $941 \mathrm{~cm}^{-1}[28,29,31]$. These bands are not observed in control experiments without ADP. However, the baseline is not completely flat due to the small amplitude of the signals and the long measurement time. The kinetic evolution of ATP production $\left(1240 \mathrm{~cm}^{-1}\right.$, black) and ADP consumption $\left(941 \mathrm{~cm}^{-1}\right.$, red) is shown in Figure 1B while the control (941 $\mathrm{cm}^{-1}$, green) sample, containing only PK and PEP, did not show any such changes. Similar plots could also be obtained for the mentioned bands of PEP and pyruvate (data not shown).

\subsection{Infrared Spectra of the Catalytic Reaction of Fumarase}

Fumarase is an enzyme which reversibly catalyses the interconversion between malate and fumarate. Figure 2A shows the absorbance spectra of malic acid (a) and fumaric acid (b) at $\mathrm{pH} 7.5$.

The absorption band at $1568 \mathrm{~cm}^{-1}$ in the malic acid spectrum and that at $1562 \mathrm{~cm}^{-1}$ in the fumaric acid spectrum are attributed to the $\mathrm{COO}^{-}$antisymmetric stretching vibration. The bands of the symmetric stretching vibration were observed at 1395 and $1372 \mathrm{~cm}^{-1}$ respectively [30]. The band at $1214 \mathrm{~cm}^{-1}$ in fumaric acid is attributed to the $\mathrm{C}-\mathrm{O}(\mathrm{H})$ stretching vibration [30]. Figure 2B shows successive difference spectra of the catalytic reaction of fumarase during 30 minutes. The initial mixture contains the substrate malic acid and enzyme fumarase at $\mathrm{pH} 7.5$. As the reaction proceeds, one observes the rise of the $1372 \mathrm{~cm}^{-1}$ band of fumaric acid. The insert shows the evolution of the 1372 $\mathrm{cm}^{-1}$ band on an expanded scale. The control spectrum after $30 \mathrm{~min}$, obtained without malic acid, is shown as dotted line. For the kinetic evaluation we selected the $1372 \mathrm{~cm}^{-1}$ band because this band was not overlapped (see control) with any other band. The kinetics of the $1372 \mathrm{~cm}^{-1}$ band is shown in 
Figure $2 \mathrm{C}$ and reflects the formation of the product. The equilibrium of the reaction was reached approximately within 12 minutes. The control did not show a signal at this wavenumber.

Figure 1. Enzymatic reaction of PK. (A) Series of overlaid spectra (solid lines) of infrared absorbance changes upon PEP and ADP addition to PK, observed for $30 \mathrm{~min}$. The solid line spectra were recorded at $12 \mathrm{~s}$ (black), $4 \mathrm{~min}$ (red), $8 \mathrm{~min}$ (green), $16 \mathrm{~min}$ (blue) and $30 \mathrm{~min}$ (cyan). The dotted line is the last spectrum $(30 \mathrm{~min}$ ) of the control experiments (shifted up). (B) Kinetics of the enzymatic reaction of PK, monitored by integrated band intensities at $1240 \mathrm{~cm}^{-1}$ (black) and $941 \mathrm{~cm}^{-1}$ (red) and the control experiment $\left(941 \mathrm{~cm}^{-1}\right.$, green). Time zero is the time when recording of the first spectrum after the background spectrum started.
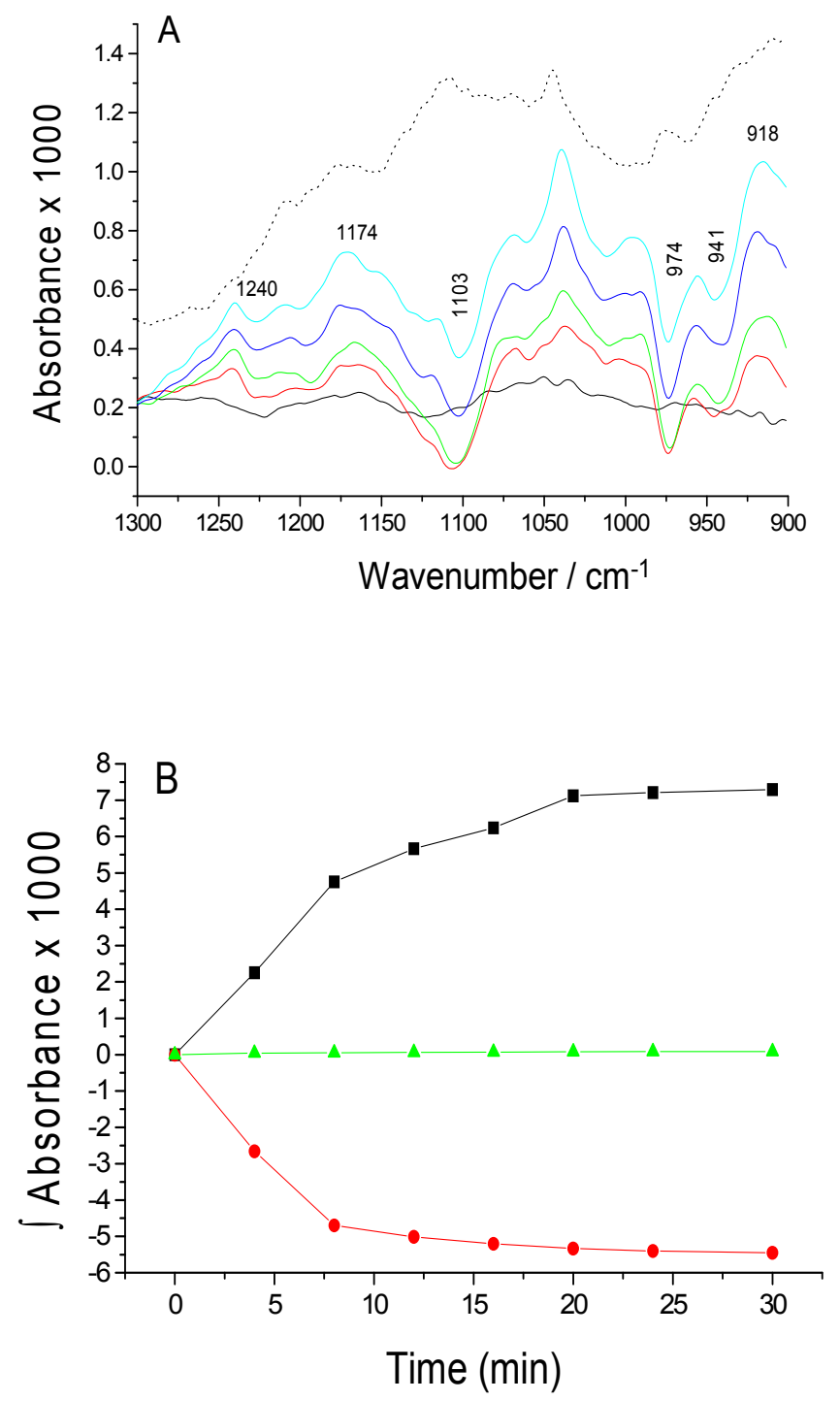
Figure 2. (A) Infrared spectra of $100 \mathrm{mM}$ malate (trace a) and fumarate (trace b) in $\mathrm{H}_{2} \mathrm{O}$ at $\mathrm{pH}$ 7.5. (B) Series of overlaid spectra of infrared absorbance changes due to the malic acid to fumarate reaction. The solid line spectra were recorded at $12 \mathrm{~s}$ (black), $4 \mathrm{~min}$ (red), $8 \mathrm{~min}$ (green), $16 \mathrm{~min}$ (blue) and $30 \mathrm{~min}$ (cyan) and the dotted line spectrum is the last spectrum of the control experiments without malic acid $(30 \mathrm{~min})$. The insert in panel B is an expanded view of the $1372 \mathrm{~cm}^{-1}$ band. (C) Kinetics of the enzymatic reaction of fumarase, monitored by the integrated band intensity at $1372 \mathrm{~cm}^{-1}$ for reaction (black) and the control (red) experiments.
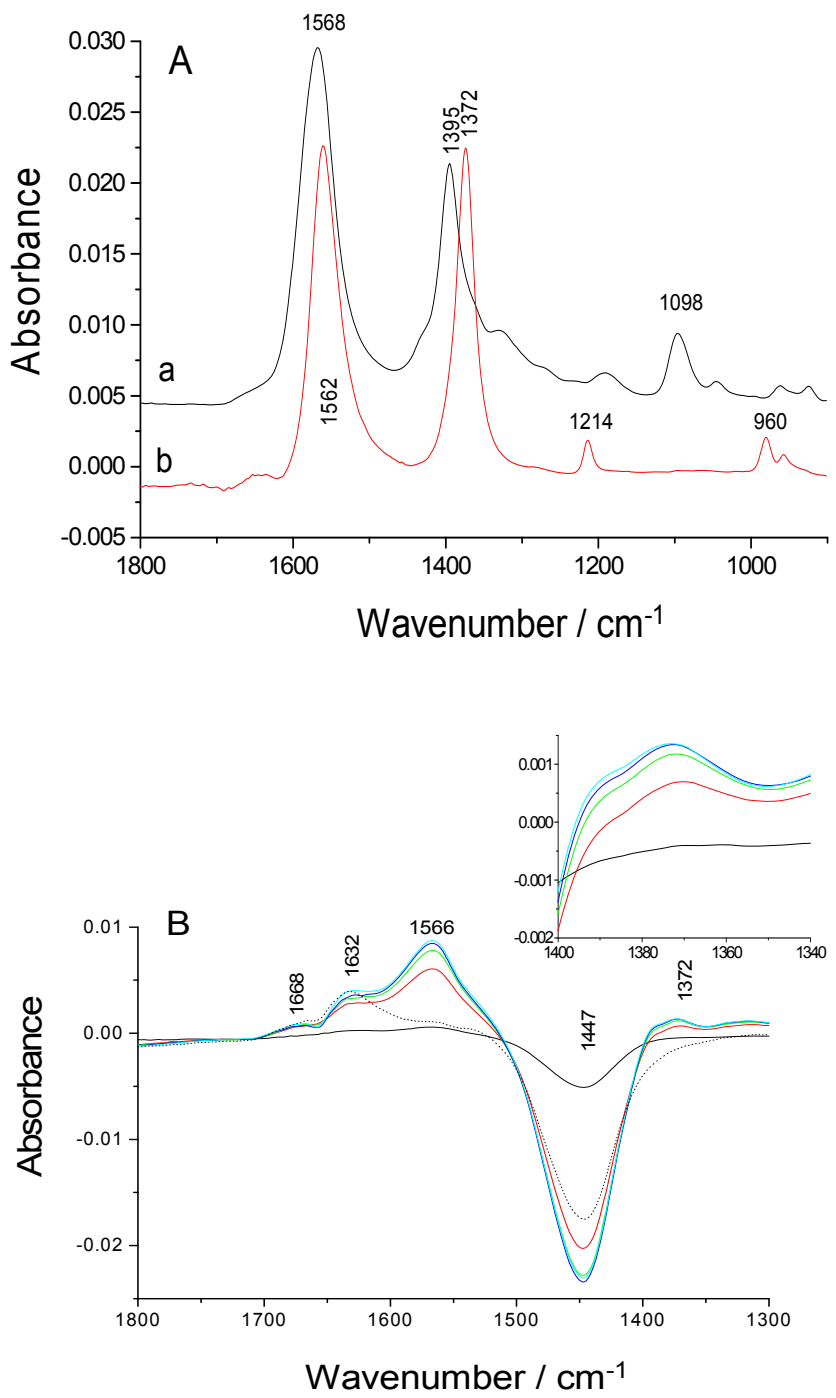
Figure 2. Cont.

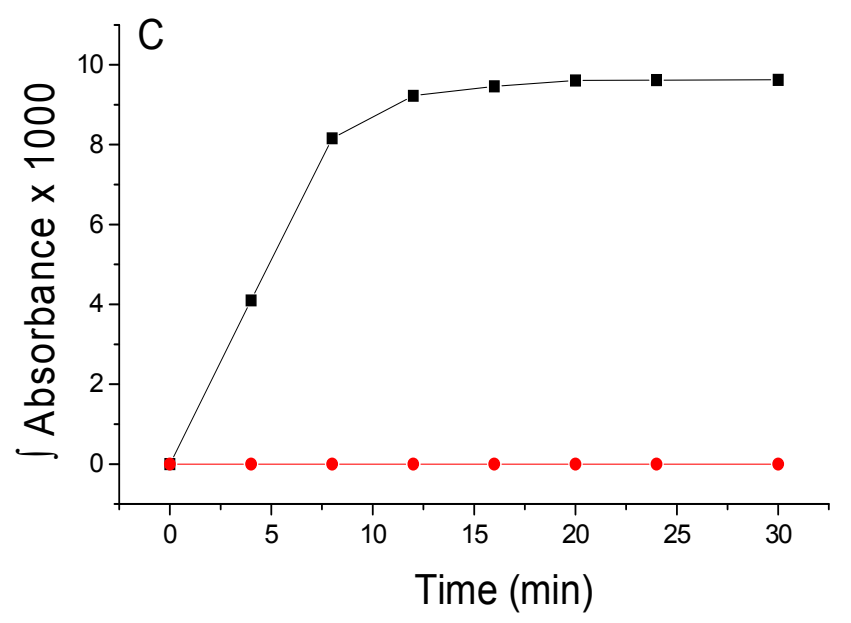

\subsection{Infrared Difference Spectra of the Catalytic Reaction of $A D H$}

Alcohol dehydrogenase catalyses the interconversion between ethanol and acetaldehyde. The difference spectra of ethanol consumption and acetaldehyde formation are shown in Figure $3 \mathrm{~A}$. They were taken during 30 minutes after mixing enzyme and substrate. Negative bands at 1044 and $877 \mathrm{~cm}^{-1}$ indicate consumption of ethanol (solid lines) and are due to the $\mathrm{C}-\mathrm{O}$ stretching and $\mathrm{C}-\mathrm{C}$ stretching vibrations of ethanol respectively [32]. We also observed the rising of negative bands at 2981 and $2900 \mathrm{~cm}^{-1}$ from $\mathrm{CH}$ stretching vibrations (not shown in Figure 3). The control experiment (dotted line) with a sample of ADH without substrate did not show these bands. Figure 3B shows a plot of the kinetics of this reaction using the $877 \mathrm{~cm}^{-1}$ band. The equilibrium was reached approximately within 24 minutes. Again, the control did not show a signal.

Figure 3. Enzymatic reaction of $\mathrm{ADH}$. (A) Series of overlaid spectra (solid line) of infrared absorbance changes upon ethanol addition to $\mathrm{ADH}$, recorded for 30 minutes. The spectra in solid line were recorded at $12 \mathrm{~s}$ (black), $4 \mathrm{~min}$ (red), $8 \mathrm{~min}$ (green), $16 \mathrm{~min}$ (blue) and $30 \mathrm{~min}$ (cyan). The dotted line is the last spectrum (30 min) of the control experiments without substrate. (B) Kinetics of the enzymatic reaction of $\mathrm{ADH}$ monitored by the integrated band intensity at $877 \mathrm{~cm}^{-1}$ for reaction (black) and the control (red) experiments.

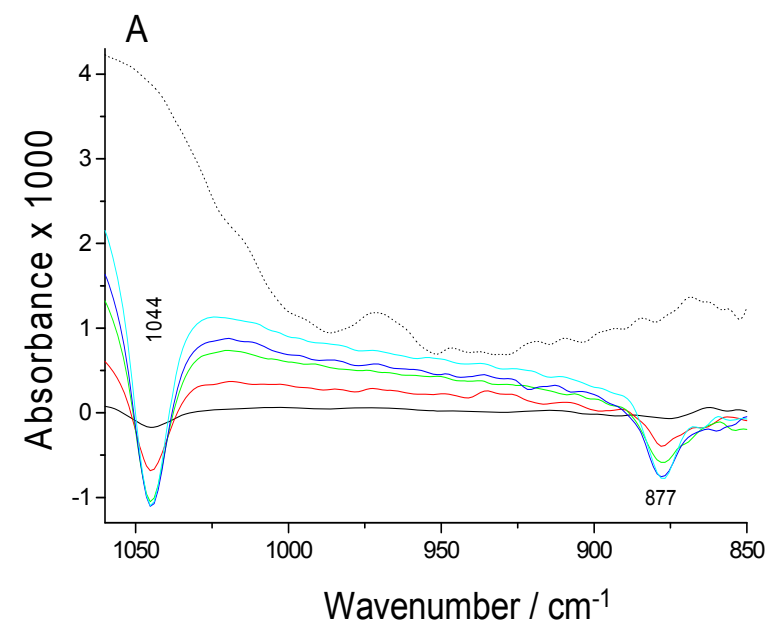


Figure 3. Cont.

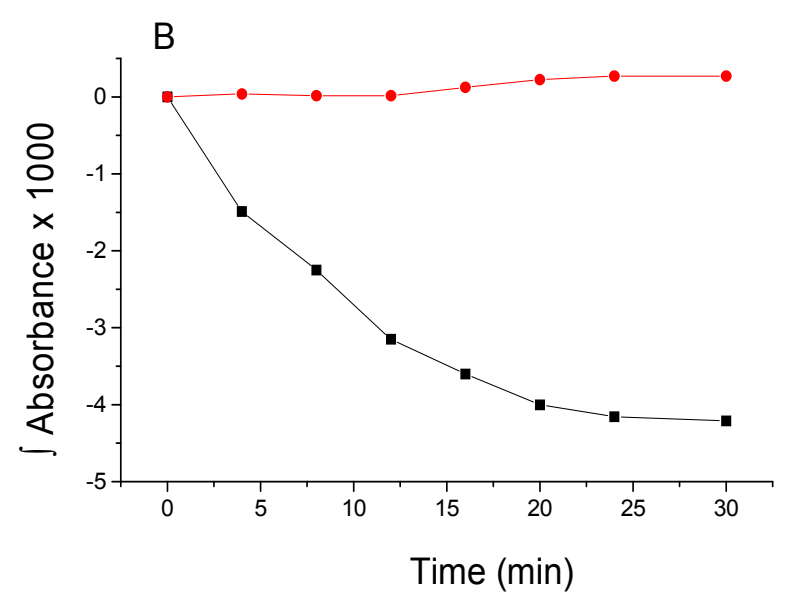

\section{Experimental Procedures}

\subsection{Materials}

PK from rabbit muscle, ADH from Saccharomyces cerevisiae, fumarase from porcine heart, monopotassium salt of PEP, pyruvate, $\mathrm{ADP}, \mathrm{NADH}^{+}$(nicotinamide adenine dinucleotide reduced), MOPS (3-[ $N$-morpholino]propanesulphonic acid) and potassium phosphate monobasic were purchased from Sigma. Tris- $\mathrm{HCl}$ was obtained from Angus. Potassium chloride $(\mathrm{KCl})$, zinc chloride $\left(\mathrm{ZnCl}_{2}\right)$ and magnesium chloride $\mathrm{MgCl}_{2}$ ) were obtained from Scharlau.

\subsection{Protein Sample Preparation}

For PK: $0.21 \mathrm{mM}(15$ units $/ \mu \mathrm{L})$ rabbit muscle $\mathrm{PK}$ was prepared in buffer $(50 \mathrm{mM}$ Tris- $\mathrm{HCl}+$ MOPS, $\mathrm{pH} 7.5$ ) containing $100 \mathrm{mM} \mathrm{KCl}$ and $5 \mathrm{mM}$ of $\mathrm{MgCl}_{2} .100 \mathrm{mM}$ of PEP and ADP were dissolved in the above buffer and the $\mathrm{pH}$ adjusted to 7.5 .

For fumarase: $0.034 \mathrm{mM}$ porcine heart fumarase was prepared in buffer $(50 \mathrm{mM}$ Tris- $\mathrm{HCl}+\mathrm{MOPS}$, $\mathrm{pH}$ 7.5) containing $100 \mathrm{mM} \mathrm{KCl}$ and $5 \mathrm{mM}$ of $\mathrm{MgCl}_{2}$. Malic acid $100 \mathrm{mM}$ was dissolved in the above buffer.

For ADH: $0.35 \mathrm{mM}(15$ units $/ \mu \mathrm{L})$ Saccharomyces cerevisiae ADH were prepared in buffer $(50 \mathrm{mM}$ Tris- $\mathrm{HCl}+$ MOPS, $\mathrm{pH} 8.8$ ) containing $100 \mathrm{mM} \mathrm{KCl}$ and $5 \mathrm{mM} \mathrm{ZnCl}_{2}$. Ethanol (200 $\left.\mathrm{mM}\right)$ was dissolved in the above buffer.

\subsection{FTIR Studies}

FTIR spectra were recorded at $4 \mathrm{~cm}^{-1}$ resolution on a Bruker Vertex 70 FTIR spectrometer equipped with an $\mathrm{HgCdTe}$ detector using a SensIR ATR setup for liquid samples with a diamond reflection element.

For PK: $5 \mu \mathrm{L}$ PK, $8 \mu \mathrm{L}$ ADP and $7 \mu \mathrm{L}$ of PEP from the above stock solutions were mixed in a vial, $20 \mu \mathrm{L}$ of mixed sample was placed on the ATR diamond reflection element and the sample trough closed with a lid to avoid evaporation of the sample. The final concentrations were as follows: $0.052 \mathrm{mM}$ (60 $\mu \mathrm{g}$ per measurement) PK, $25 \mathrm{mM}$ ADP $(85 \mu \mathrm{g})$ and $25 \mathrm{mM}$ PEP (35.5 $\mu \mathrm{g})$. Then, a 300 scan single beam spectrum (background spectrum) and repeated spectra in the absorption mode (150 scans each) were recorded for 30 minutes. It took around $50 \mathrm{~s}$ to prepare the reaction mixture (15 s) 
and to measure the background spectrum ( $35 \mathrm{~s})$, this was followed by recording of the first spectrum (12 s) and spectra recording for further 30 minutes. The control samples contained PK and PEP in the same above concentrations but no ADP and the measurements were performed in the same way as for the reaction mixture. We averaged four samples for activity measurement and three samples for the controls.

For fumarase: $15 \mu \mathrm{L}$ fumarase, $5 \mu \mathrm{L}$ malic acid from the above stock solutions were mixed in a vial and $20 \mu \mathrm{L}$ of mixed sample was placed on the ATR diamond reflection element. The final concentrations of the reaction mixture were $0.0255 \mathrm{mM}$ fumarase $(74.2 \mu \mathrm{g}$ per measurement) and $25 \mathrm{mM}$ malic acid $(17 \mu \mathrm{g})$. The control samples contained the same amount of fumarase but no malic acid. Spectra were recorded as stated above. We averaged four samples for activity measurement and three samples for the controls. For recording absorption spectra, $100 \mathrm{mM}$ malic acid and fumaric acid were dissolved in water and the $\mathrm{pH}$ was adjusted to 7.5.

For ADH: $1 \mu \mathrm{L} \mathrm{ADH}$ and $19 \mu \mathrm{L}$ ethanol $(200 \mathrm{mM})$ from the above stock solutions were mixed in a vial and $20 \mu \mathrm{L}$ of mixed sample was placed on the ATR diamond reflection element. The final concentrations of the reaction mixture were $0.0175 \mathrm{mM} \mathrm{ADH}(3.5 \mu \mathrm{g}$ per measurements) and $190 \mathrm{mM}$ ethanol $(175 \mu \mathrm{g})$. The control samples contained $0.0175 \mathrm{mM}(3.5 \mu \mathrm{g})$ of ADH. Spectra were recorded as stated above. We averaged four samples for activity measurement and three samples for the controls.

For the kinetic evaluation of particular bands in a series of difference spectra, the band was integrated around its maximum with respect to a baseline drawn through two data points on both sides of the maximum. Each of these points was the average of several data points near the base of the band. The spectral range for the baseline points was broad when there was no overlap with other bands, it was narrow and closer to the position of the band maximum when other bands were superimposing. This results in integrated band areas which are highly specific for the band studied and little affected by baseline drifts or overlap with other bands.

\section{Conclusions}

This work demonstrates the benefits of infrared spectroscopy for monitoring enzymatic reactions. Substrates and products can be observed directly without the need of time-consuming assay development. Here we studied enzyme activity of PK, fumarase and ADH using commercial equipment. For all three enzymes, we followed their activity by observing either reactant consumption or product formation or both (phosphoenolpyruvate, ADP, ethanol and fumaric acid) by using a particular infrared absorption band of these molecules. Kinetic data were obtained by using only $\leq 1 \mathrm{nmol}$ enzyme ( $1 \mathrm{nmol}$ PK, $0.5 \mathrm{nmol}$ fumarase, $0.35 \mathrm{nmol}$ ADH) and $\sim \mu \mathrm{mol}$ substrate $(0.5 \mu \mathrm{mol}$ PEP, ADP, and malic acid and $4 \mu \mathrm{mol}$ ethanol). If quantitative activity measurements are necessary, the signal amplitudes of the kinetic experiments can easily be expressed in absolute concentrations by comparison with absorption spectra of reactants and/or products at known concentrations. 


\section{Acknowledgements}

We are grateful to Sven och Lilly Lawskis fond för naturvetenskaplig forskning for a PhD stipend to S.K. and thank Knut och Alice Wallenberg Stiftelse for funding the spectrometer. The running costs were provided by Vetenskapsrådet.

\section{References}

1. Jencks, W.P. Infrared measurements in aqueous media. Methods Enzymol. 1963, 6, 914-928.

2. Karmali, K.; Karmali, A.; Teixeira, A.; Curto, M.J.M. The use of Fourier transform infrared spectroscopy to assay for urease from Pseudomonas aeruginosa and Canavalia ensiformis. Anal. Biochem. 2004, 331, 115-121.

3. Fisher, J.; Belasco, J.G.; Khosla, S.; Knowles, J.R. ß-Lactamase proceeds via an acyl-enzyme intermediate. Interaction of the Escherichia coli RTEM enzyme with cefoxitin. Biochemistry 1980, 19, 2895-2901.

4. White, A.J.; Drabble, K.; Ward, S.; Wharton, C.W. Analysis and elimination of protein perturbation in infrared difference spectra of acyl-chymotrypsin ester carbonyl groups by using ${ }^{13} \mathrm{C}$ isotopic substitution. Biochem. J. 1992, 287, 317-323.

5. Barth, A.; Mäntele, W.; Kreutz, W. Infrared spectroscopic signals arising from ligand binding and conformational changes in the catalytic cycle of sarcoplasmic reticulum $\mathrm{Ca}^{2+}$-ATPase. Biochim. Biophys. Acta 1991, 1057, 115-123.

6. Barth, A.; Mäntele, W.; Kreutz, W. Molecular changes in the sarcoplasmic reticulum $\mathrm{Ca}^{2+}$ ATPase during catalytic activity. A Fourier transform infrared (FTIR) study using photolysis of caged ATP to trigger the reaction cycle. FEBS Lett. 1990, 277, 147-150.

7. Thoenges, D.; Barth, A. Direct measurement of enzyme activity with infrared spectroscopy. $J$. Biomol. Screen. 2002, 7, 353-357.

8. López-Sánchez, M.; Ayora-Cañada, M.J.; Molina-Díaz, A.; Siam, M.; Huber, W.; Quintás, G.; Armenta, S.; Lendl, B. Determination of enzyme activity inhibition by FTIR spectroscopy on the example of fructose bisphosphatase. Anal. Bioanal. Chem. 2009, 394, 2137-2144.

9. Lendl, B.; Krieg, P.; Kellner, R. Determination of alkaline phosphatase activity in human sera by mid-FTIR spectroscopy. Fresenius J. Anal. Chem. 1998, 360, 717-720.

10. Karmali, K.; Karmali, A.; Teixeira, A.; Curto, M.J.M. Assay for glucose oxidase from Aspergillus niger and Penicillium amagasakiense by Fourier transform infrared spectroscopy. Anal. Biochem. 2004, 333, 320-327.

11. Cadet, F.; Pin, F.W.; Rouch, C.; Robert, C.; Baret, P. Enzyme kinetics by mid-infrared spectroscopy: ß-fructosidase study by a one-step assay. Biochim. Biophys. Acta 1995, 1246, 142-150.

12. Schindler, R.; Le Thannh, H.; Lendl, B.; Kellner, R. Determination of enzyme kinetics and chemometric evaluation of reaction products by FTIR spectroscopy on the example of ß-fructofuranosidase. Vib. Spectrosc. 1998, 16, 127-135.

13. Schindler, R.; Lendl, B. Simultaneous determination of enzyme activities by FTIR-spectroscopy in an one-step assay. Anal. Chim. Acta 1999, 391, 19-28. 
14. Schindler, R.; Lendl, B.; Kellner, R. Determination of amyloglucosidase activity using flow injection analysis with Fourier transform infrared spectrometric detection. Analyst 1997, 122, 531-534.

15. Schindler, R.; Lendl, B.; Kellner, R. Simultaneous determination of $\alpha$-amylase and amylogucosidase activities using flow injection analysis with Fourier transform infrared spectroscopic detection and partial least-squares data treatment. Anal. Chim. Acta. 1998, 366, 35-43.

16. Krieg, P.; Lendl, B.; Vonach, R.; Kellner, R. Determination of $\alpha$-amylase activity using Fourier transform infrared spectroscopy. Fresenius J. Anal. Chem. 1996, 356, 504-507.

17. Pacheco, R.; Serralheiro, M.L.M.; Karmali, A.; Haris, P.I. Measuring enzymatic activity of a recombinant amidase using Fourier transform infrared spectroscopy. Anal. Biochem. 2003, 322, 208-214.

18. Pacheco, R.; Karmali, A.; Serralheiro, M.L.M.; Haris, P.I. Application of Fourier transform infrared spectroscopy for monitoring hydrolysis and synthesis reactions catalysed by a recombinant amidase. Anal. Biochem. 2005, 346, 49-58.

19. Gäb, J.; Melzer, M.; Kehe, K.; Richardt, A.; Blum, M.M. Quantification of hydrolysis of toxic organophosphates and organophosphonates by diisopropyl fluorophosphatasse from Loligo vulgaris by in situ Fourier transform infrared spectroscopy. Anal. Biochem. 2009, 385, 187-193.

20. Wright, W.; Vanderkooi, J.M. Use of IR absorption of the carboxyl group of amino acids and their metabolites to determine pKs, to study proteins, and to monitor enzymatic activity. Biospectroscopy 1997, 3, 457-467.

21. Muthusamy, M.; Burrell, M.R.; Thorneley, R.N.F.; Bornemann, S. Real-time monitoring of the oxalate decarboxylase reaction and probing hydron exchange in the product, formate, using Fourier transform infrared spectroscopy. Biochemistry 2006, 45, 10667-10673.

22. Kansiz, M.; Gapes, J.R.; McNaughton, D.; Lendl, B.; Schuster, K.C. Mid-infrared spectroscopy coupled to sequential injection analysis for the on-line monitoring of the acetone-butanol fermentation process. Anal. Chim. Acta 2001, 438, 175-186.

23. Seeholzer, S.H.; Jaworowski, A.; Rose, I.A. Enolpyruvate: chemical determination as a pyruvate kinase intermediate. Biochemistry 1991, 30, 727-732.

24. Rose, I.A. Stereochemistry of pyruvate kinase, pyruvate carboxylase, and malate enzyme reactions. J. Biol. Chem. 1970, 245, 6052-6056.

25. Ocha, S. The Enzyme; Summer, B., Mybrack, K., Eds.; Academic press, Inc.: New York, NY, USA, 1951; Volume I, part 2, chapter 40.

26. Kumar, S.; Barth, A. Phosphoenolpyruvate and $\mathrm{Mg}^{2+}$ binding to pyruvate kinase monitored by infrared spectroscopy. Biophys. J. 2010, in press.

27. Rudbeck, M.E.; Kumar, S.; Mroginski, M.A.; Lill, S.O.N.; Blomberg, M.R.A; Barth, A. Infrared spectrum of phosphoenolpyruvate: computational and experimental studies. J. Phys. Chem. A. 2009, 113, 2935-2942.

28. Barth, A.; Mäntele, W. ATP-induced phosphorylation of the sarcoplasmic reticulum $\mathrm{Ca}^{2+}$ ATPase: molecular interpretation of infrared difference spectra. Biophys. J. 1998, 75, 538-544.

29. Takeuchi, H.; Murata, H.; Harada, I. Interaction of adenosine 5 -triphosphate with $\mathrm{Mg}^{2+}$ : vibrational study of coordination sites by use of ${ }^{18} \mathrm{O}$-labeled triphosphates. J. Am. Chem. Soc. 1988, 110, 392-397. 
30. Colthup, N.B.; Daly, L.H.; Wiberley, S.E. Introduction to Infrared and Raman Spectroscopy; 2nd Ed.; Academic Press: New York, NY, USA, 1975.

31. Wang, J.H.; Xiao, D.G.; Deng, H.; Callender, R.; Webb, M.R. Vibrational study of phosphate modes in GDP and GTP and their interaction with magnesium in aqueous solution. Biospectroscopy 1998, 4, 219-227.

32. Mikawa, Y; Brasch, J.W.; Jakobsen, R.J. Polarized infrared spectra of single crystal of ethyl alcohol. Spectrochim. Acta 1971, 27, 529-539.

(C) 2010 by the authors; licensee Molecular Diversity Preservation International, Basel, Switzerland. This article is an open-access article distributed under the terms and conditions of the Creative Commons Attribution license (http://creativecommons.org/licenses/by/3.0/). 